\title{
Erratum to: Global Health Workforce Labor Market Projections for 2030
}

Jenny X. Liu', Yevgeniy Goryakin², Akiko Maeda², Tim Bruckner ${ }^{3}$ and Richard Scheffler ${ }^{4}$

\section{Erratum}

After this article [1] was published the authors noticed that the wrong version of Fig. 1 had been uploaded. The Correct figure, is shown below.

\begin{abstract}
Author details
'Institute for Health and Aging, Department of Social and Behavioral Sciences, University of California, San Francisco, 3333 California Street, Suite 340, San Francisco, CA 94118, United States of America. ${ }^{2}$ Health Division, Labour and Social Affairs, Organization for Economic Co-operation and Development, 2 rue Andre Pascal, Cedex 16, 75775 Paris, France. ${ }^{3}$ School of Public Health, University of California, 635 E. Peltason Dr., 92697-3957 Irvine, CA, United States of America. ${ }^{4}$ School of Public Health, Goldman School of Public Policy, University of California, Berkeley, 50 University Hall MC7360,

94704 Berkeley, CA, United States of America.
\end{abstract}

Received: 6 February 2017 Accepted: 14 February 2017

Published online: 20 February 2017

\section{Reference}

1. Liu JX, Goryakin Y, Maeda A, Bruckner T, Scheffler R. Global Health

Workforce Labor Market Projections for 2030. Hum Resour Health. 15:11. doi:

10.1186/s12960-017-0187-2

\footnotetext{
* Correspondence: Jenny.Liu2@ucsf.edu

${ }^{1}$ Institute for Health and Aging, Department of Social and Behavioral

Sciences, University of California, San Francisco, 3333 California Street, Suite

340, San Francisco, CA 94118, United States of America
} 


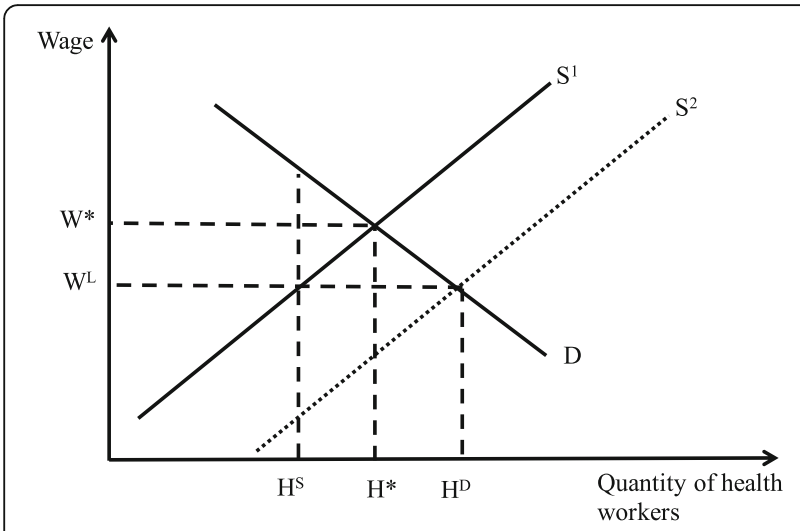

Fig. 1 Health worker static labor market theoretical framework. Legend: Demand (D) and supply (S) interact to determine the number of workers $\left(H^{*}\right)$ that will be employed at a market wage rate $\left(W^{*}\right)$. At a wage rate $\left(W^{L}\right)$ that is lower than the market optimum $\left(W^{*}\right)$, a shortage of workers results, and the number of workers demanded $\left(H^{D}\right)$ exceeds the number supplied $\left(H^{S}\right)$. To alleviate shortages in this market, either (1) additional compensation could be given to increase wages to $\mathrm{W}^{*}$ and attract more workers into the market, or (2) the production of workers could be increased such that supply shifts outward $\left(\mathrm{S}^{2}\right)$ and the quantity demand $\left(\mathrm{H}^{\mathrm{D}}\right)$ is achieved while keeping wages at $W^{L}$ 